\title{
Impact of treatment with oxidative bleaching agents on walnut (Juglans Regia L.) shell chromatic parameters
}

\section{Eugenia Boaghi}

Technical University of Moldova, Chisinau, Republic of Moldova

Keywords:

Walnut

Color

Bleaching

Okoron 12

Hydrogen peroxide

Sodium perborate

Calcium hypochlorite

Article history:

Received 26.09.2016

Received in revised form 12.12.2016

Accepted 27.12.2016

\section{Corresponding author:}

Eugenia Boaghi

E-mail:

eugenia.boaghi@

toap.utm.md

DOI: $10.24263 / 2304-$

974X-2016-5-4-4

\section{Abstract}

Introduction. Walnuts were formerly marketed in an unbleached condition, but the demand of the trade has led to the general practice of bleaching. Some walnuts are still sold in an unbleached condition, but most of those destined for out-of-state markets must be bleached. The objectives of this study are to present the effect of different bleaching agents on walnuts (Juglans Regia L.) shell.

Materials and methods. For color quantifying it was used the most popular color space system for measuring color of agricultural products - the Commission International de l'Esclairage (CIE) color system which uses the $\mathrm{L}^{*}, \mathrm{a}^{*}$, and $\mathrm{b}^{*}$ indices. Also, the total color difference $(E)$, a single value which takes into account the differences between the $L^{*}, a^{*}$, and $b^{*}$ of the sample and standard was calculated.

Results and discussion. Analyzing the obtained values for cromatic parameters for each of used bleaching agents it was esteblished that those vary depending on the bleaching agent, concentration, $\mathrm{pH}$ of the medium, temperature and retention time of walnuts in bleach. The concentration has a major significance, with its growth reduces the time required to achieve an expected result. The $\mathrm{pH}$ of the medium plays an important role in the catalytic oxidation. Speed of walnut shell bleaching and brightness $(L)$ increase with increasing $\mathrm{pH}$ from 3 to 10 . The studied agents form the following series of bleaching activity: $\mathrm{Na}_{2} \mathrm{~B}_{2} \mathrm{O}_{4}(\mathrm{OH})_{4}>$ Okoron $12>\mathrm{H}_{2} \mathrm{O}_{2}>\mathrm{Ca}(\mathrm{ClO})_{2}$. It has been established that the optimal conditions for bleaching with $\mathrm{Na}_{2} \mathrm{~B}_{2} \mathrm{O}_{4}(\mathrm{OH})_{4}$ are: $\mathrm{C}=5 \%, \mathrm{pH}=10 ; \mathrm{t}=$ $60{ }^{\circ} \mathrm{C}$.

Conclusions. All bleaching agents proved to be suitable to lighten the walnut shell. In comparison with the widely used $\mathrm{H}_{2} \mathrm{O}_{2}$ the ageing process developed simultaneously, but there were differences in the total lightness change, the Sodium perborate treated samples stayed lighter. 


\section{Introduction}

The walnut tree (Juglans regia L.) is cultivated commercially throughout southern Europe, northern Africa, Eastern Asia, the USA and western South America [1].

Walnut cultivars differ in the ability to produce light-coloured kernels under different climatic conditions. Important quality factors of walnuts are the size, colour, level of internal damage caused by insects, and level of external damage, such as adhering hull tissue and broken shells [2].

In Moldova, the walnut sector has seen rapid growth, from a very low base, in recent years, founded on three factors: the comparative advantage in production, the presence of a low cost labour force which is able to extract manually for the confectionary market with a much higher extraction rate of unbroken kernels than mechanised methods, and preferential access to the EU market with no tariff duties. The result has been a proliferation of marketing and processing operators. In recent years the walnut production has grown from 22700 in 2012 to 31000 metric tons, in shell basis in 2016 [3].

Color of the food is the first parameter of quality evaluated by consumers. What is important is the acceptance of the product even before being consumed.

Food colour is governed by thechemical, biochemical, microbial and physical changes which occur during growth, maturation, postharvest handling and processing.

Most walnuts of good commercial quality have shells of a brownish straw color and in some instances the shells will be of a light straw color which is more favored in the trade. Walnuts were formerly marketed in an unbleached condition, but the demand of the trade has led to the general practice of bleaching. Some walnuts are still sold in an unbleached condition, but most of those destined for out-of-state markets must be bleached. In general, the quality of the walnut kernel is not indicated by the color of the shell, but it is the general practice in the nut-packing industries to bleach the shells in order to produce a more attractive appearance' in view of the preference which buyers exhibit for light-colored nuts. Walut shell is composed of constituents responsible for its skeleton: cellulose, hemicellulose, lignin and chemical compounds responsible for color: phenols, quinones, coumarins, tannins and flavonoids, studies and research have shown, however, that lignin is involved in the color changing.

About $25.16 \%$ cellulose, $21,32 \%$ hemicelluloses, and $53.52 \%$ lignin were reported in the Walnut shel [4].

Bleaching is the treatment of cellulose with chemical solutions in order to lighten the color or discoloration. Brightness can be carried out by solubilization and removal of lignin, a macromolecular aromatic compound that confers rigidity, cloak to water and a high resistance to decomposition, at the same time has an influence on walnut shell color changing.

Besides removing lignin, bleaching serves to disinfect the walnuts from mold spores that can result from processes of mesocarp traces decay. Besides lignin, extractive substances also have an influence on the phenomenon of color change or fading.

Both oxidizing and reductive agents are used for bleaching cellulosic products. In reactions caused by the treating agents the number of covalent bonds in cellulose, hemi cellulose and lignin is reduced. With the decreasing number of covalent bonds the color of the wood appears lighter.

Nowdays, the bleaching agents are based primarily on hydrogen peroxide (HP). The bleaching agents provide whitening of cellulosic products through decomposition of peroxides into unstable free radicals. These radicals further breakdown into large pigmented molecules either through an oxidation or a reduction reaction, that leads to the change of the chemical structure of product interacting organic substances, which results in color change $[5,6]$. 


\section{— Food Technologies —}

\section{Materials and methods}

\section{Materials}

Walnult fruits, variety Calarasi, were collected from local walnut plantation, Iargara, Moldova. All chemicals used for experiments were at least analytical grade.

\section{Sample preparation}

The walnut samples were cleaned to remove trash and damaged, sunburned, and broken walnuts.

\section{Bleaching}

For walnut bleaching were selected oxidising agents: $\mathrm{H}_{2} \mathrm{O}_{2}$, Okoron $12, \mathrm{Na}_{2} \mathrm{~B}_{2} \mathrm{O}_{4}(\mathrm{OH})_{4}$ and $\mathrm{Ca}(\mathrm{ClO})_{2}$ (concentrations in the neighborhood of $1-10 \%$ being found satisfactory). The process was performed in the temperature range $-20-60{ }^{\circ} \mathrm{C}$ and at the $\mathrm{pH}$ range 3 to $10(\mathrm{pH}$ adjusted with $\mathrm{HCl}$ or $\mathrm{NaOH}$ to the desired value).

Prepared walnut samples were immersed in the solution of bleaching agent being agitated to insure complete contact, the time of retention varied from 10 to $120 \mathrm{~min}$, being considered as a sufficient period to secure thorough impregnation of the shells, after which the walnuts were withdrawn from the solution'and allowed to dry.

\section{Quantification of Colour}

CIELAB analysis are used in many different experiments in organic chemistry [7], anorganic chemistry [8], and in food chemistry as well.

All color data were expressed by $\mathrm{L}^{*}, \mathrm{a}^{*}, \mathrm{~b}^{*}$, where $\mathrm{L}^{*}$ corresponds to lightness; $\mathrm{a}^{*}$ corresponds to the transition from green $\left(-a^{*}\right)$ to red $\left(+a^{*}\right)$; and $b^{*}$ corresponds to the transition from blue $\left(-b^{*}\right)$ to yellow $\left(+b^{*}\right)$. The international standards and the nomenclature for the measurement of color used by the food industry were defined by the Commission Internationale de l'éclairage (CIE) in 1931. In the present study, the CIELAB system $\left(\mathrm{L}^{*}, \mathrm{a}^{*}, \mathrm{~b}^{*}\right)$ was used.

Colour change was calculated acc. to the following formula [PN-ISO 105- B02:2006]:

$$
\Delta E=\sqrt{(\Delta L)^{2}+(\Delta a)^{2}+(\Delta b)^{2}}
$$

where: $\Delta \mathrm{E}$ - colour difference, $\mathrm{L}-$ colour achromatic coordinate (lightness); $\mathrm{L}=100$ indicates approximation of a given colour to white, and $\mathrm{L}=0$ to black, $\mathrm{a}, \mathrm{b}-$ colour chromatic coordinates; $(+$ a) indicates red colour, $(-a)$ indicates green colour, $(+b)$ indicates yellow colour, $(-b)$ indicates blue colour. The measurement of colour coordinates $\mathrm{L}^{*}, \mathrm{a}^{*}, \mathrm{~b}^{*}$ of walnuts before and after bleaching was done in the same, accurately marked places.

Hue angle $\left(\mathrm{h}^{*}\right)$ and chroma $\left(\mathrm{C}^{*}\right)$ are two effective parameters for describing visual color appearance [9-11]. The $\mathrm{h}^{*}$ and $\mathrm{C}^{*}$ values were calculated using the following Eqs. [12]:

$$
\begin{gathered}
h=\tan ^{-1} \frac{b}{a} \\
c=\sqrt{\left(a^{2}+b^{2}\right)}
\end{gathered}
$$




\section{Results and discussion}

There were no literary data available on the mechanism of bleaching with some agents, thus the first question was whether are they effective or not for bleaching walnuts and in how much time a 1 to $10 \%$ concentration will manifest its effect.

The results of walnuts bleahing with all used bleaching agents according their concentration are presented in Tables $1-4$.

The effect of hydrogen peroxide concentration

Table 1 on chromatic parameters of walnuts shell

\begin{tabular}{|c|c|c|c|c|c|c|c|}
\hline $\mathbf{C ,}$ \% & $\mathbf{t , ~} \mathbf{m i n}$ & $\mathbf{a}$ & $\mathbf{b}$ & $\mathbf{L}$ & $\mathbf{\Delta E}$ & $\mathbf{h}$ & $\mathbf{C}$ \\
\hline \multirow{4}{*}{3} & $\mathbf{1 0}$ & 2.8 & 28.23 & 42.94 & 11.46 & 1.47 & 28.37 \\
\cline { 2 - 8 } & $\mathbf{3 0}$ & 2.38 & 30.52 & 46.96 & 15.29 & 1.49 & 30.61 \\
\cline { 2 - 8 } & $\mathbf{6 0}$ & 2.3 & 32.27 & 51.09 & 18.46 & 1.50 & 32.35 \\
\cline { 2 - 8 } & $\mathbf{9 0}$ & 2.01 & 33.2 & 58.48 & 22.98 & 1.51 & 33.26 \\
\cline { 2 - 8 } & $\mathbf{1 2 0}$ & 1.89 & 33.9 & 60.59 & 23.81 & 1.52 & 33.95 \\
\hline \multirow{4}{*}{6} & $\mathbf{1 0}$ & 2.34 & 30.24 & 45.42 & 12.93 & 1.49 & 30.33 \\
\cline { 2 - 8 } & $\mathbf{3 0}$ & 2.06 & 31.68 & 54.96 & 17.42 & 1.51 & 31.75 \\
\cline { 2 - 8 } & $\mathbf{6 0}$ & 1.8 & 32.96 & 58.11 & 21.17 & 1.52 & 33.01 \\
\cline { 2 - 8 } & $\mathbf{9 0}$ & 1.6 & 34.2 & 62.35 & 23.25 & 1.52 & 34.24 \\
\cline { 2 - 8 } & $\mathbf{1 2 0}$ & 1.55 & 34.61 & 63.43 & 24.96 & 1.53 & 34.64 \\
\hline \multirow{4}{*}{8} & $\mathbf{1 0}$ & 1.68 & 31.1 & 54.76 & 15.56 & 1.52 & 31.15 \\
\cline { 2 - 8 } & $\mathbf{3 0}$ & 1.2 & 34.65 & 59.81 & 20.66 & 1.54 & 34.67 \\
\cline { 2 - 8 } & $\mathbf{6 0}$ & 0.9 & 35.11 & 62.53 & 22.57 & 1.55 & 35.12 \\
\cline { 2 - 8 } & $\mathbf{9 0}$ & 0.5 & 36.23 & 63.48 & 24.10 & 1.56 & 36.23 \\
\cline { 2 - 8 } & $\mathbf{1 2 0}$ & 0.1 & 36.65 & 65.7 & 25.09 & 1.57 & 36.65 \\
\hline \multirow{4}{*}{10} & $\mathbf{1 0}$ & 1.2 & 31.45 & 58.44 & 16.21 & 1.53 & 31.47 \\
\cline { 2 - 8 } & $\mathbf{3 0}$ & 0.8 & 34.78 & 64.78 & 22.02 & 1.55 & 34.79 \\
\cline { 2 - 8 } & $\mathbf{6 0}$ & 0.5 & 35.82 & 65.23 & 23.31 & 1.56 & 35.82 \\
\cline { 2 - 8 } & $\mathbf{9 0}$ & 0.3 & 37.64 & 65.96 & 24.10 & 1.56 & 37.64 \\
\cline { 2 - 8 } & $\mathbf{1 2 0}$ & 0.2 & 38.17 & 66.5 & 25.75 & 1.57 & 38.17 \\
\hline \multirow{4}{*}{} & & & & & & & \\
\hline
\end{tabular}

The results show that an important role in walnut bleaching with hydrogen peroxide plays the agent concentration. The higher the concentration is $(8-10 \%)$, the more it increases the concentration in solution, which results in decreasing the time necessary to achieve the necessary bleaching level.

The oxidation reaction is directed to the chromophore groups of lignin, destruction of which leads to the high degree of cellulose bleaching. Hydrogen peroxide bleaching occurs due to peroxide ion $\mathrm{HO}_{2}^{-}$originated as a result of hydrolytic cleavage of peroxide:

$$
\mathrm{H}_{2} \mathrm{O}_{2} \leftrightarrow \mathrm{H}^{+}+\mathrm{HO}_{2}^{-}
$$

It is believed that non etherified phenolic units of lignin are initially processed in alkaline environment in ortho and para-benzoquinones that are then subjected to oxidation to produce acid fragments. In these conditions the e etherified phenolic units are stable [13]. 
This leads to a substantial increase in the number of carboxyl groups of the lignin (Figure 1).

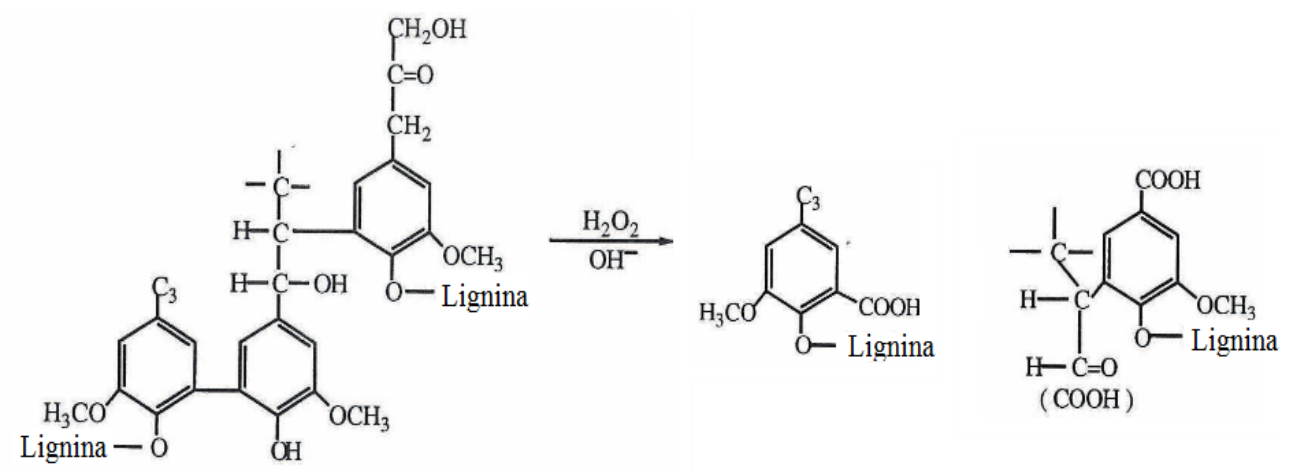

Figure 1. The reaction of the interaction of lignin with hydrogen peroxide in the bleaching

The effect of hydrogen peroxide concentration on the bleaching process was studied at four concentrations of hydrogen peroxide: $3,6,8$ and $10 \%$. The results show that increasing the concentration of hydrogen peroxide increases the brightness of the product. The initial Luminosity values of samples was 35.37 to 48.77 , and bleached samples were from 42.94 to 66.5. Analyzing the presented values (Table 1) it can be noted that there is a tendency to increase the brightness parameter.

Hypochlorite aqueous solution that is commonly used in bleaching, contains molecular chlorine, hypochlorous acid and hypochlorite ions. The molecular chlorine predominates at low $\mathrm{pH}$, at a $\mathrm{pH}$ of 4-6 basically only the hypochlorous acid is present, and at a $\mathrm{pH}$ above 9.5 the only form of active chlorine present in the solution is the hypochlorite ion.

Hypochlorite reaction with lignin stems initially quite fast and slower towards the end. In result of the reaction occurs oxidative degradation of lignin and chlorination and demethylation reactions are practically missing [14].

Analyzing the results blanching nuts with calcium hypochlorite (Table 2) was found that calcium hypochlorite bleaching which is less efficient, increasing temperature and an alkaline $\mathrm{pH}$ increases the brightness of shells and accelerates destruction of lignin and bleaching respectively. The optimum temperature is considered to be $40-45^{\circ} \mathrm{C}$ and optimal $\mathrm{pH}$ value is about 10.0 during $1.5-2.0$ hours.

Okoron 12 it is a stabilized composition, which contains peracetic acid $\mathrm{CH}_{3} \mathrm{CO}_{3} \mathrm{H}$ (15\%), hydrogen peroxide and organic acids, produced by FINK TEC GmbH (Germany) and widely used as a disinfectant. 
Table 2

The effect of calcium hypochlorite $\left(\mathrm{Ca}(\mathrm{OCl})_{2}\right)$ concentration on chromatic parameters of walnuts shell

\begin{tabular}{|c|c|c|c|c|c|c|c|}
\hline $\mathrm{C}, \%$ & $\mathbf{t}, \mathrm{min}$ & $\mathbf{a}$ & b & $\mathbf{L}$ & $\Delta \mathbf{E}$ & h & C \\
\hline \multirow{5}{*}{3} & 10 & 7.66 & 25.65 & 40.10 & 2.34 & 1.28 & 26.77 \\
\hline & 30 & 6.68 & 27.60 & 41.11 & 3.04 & 1.33 & 28.40 \\
\hline & 60 & 4.39 & 27.90 & 42.57 & 2.40 & 1.41 & 28.24 \\
\hline & 90 & 3.96 & 28.11 & 44.79 & 3.75 & 1.43 & 28.39 \\
\hline & 120 & 1.84 & 28.30 & 45.39 & 5.55 & 1.51 & 28.36 \\
\hline \multirow{5}{*}{6} & 10 & 7.18 & 28.31 & 40.76 & 3.83 & 1.32 & 29.21 \\
\hline & 30 & 6.20 & 29.10 & 43.74 & 5.61 & 1.36 & 29.75 \\
\hline & 60 & 3.90 & 29.60 & 45.77 & 7.99 & 1.44 & 29.86 \\
\hline & 90 & 2.79 & 30.10 & 45.78 & 8.29 & 1.48 & 30.23 \\
\hline & 120 & 1.29 & 30.20 & 46.37 & 8.76 & 1.53 & 30.23 \\
\hline \multirow{5}{*}{8} & 10 & 6.11 & 29.81 & 41.32 & 7.16 & 1.37 & 30.43 \\
\hline & 30 & 4.98 & 31.20 & 44.17 & 9.51 & 1.41 & 31.59 \\
\hline & 60 & 3.87 & 31.90 & 47.13 & 11.80 & 1.45 & 32.13 \\
\hline & 90 & 2.50 & 32.10 & 52.30 & 16.13 & 1.49 & 32.20 \\
\hline & 120 & 1.10 & 32.23 & 54.10 & 18.01 & 1.54 & 32.25 \\
\hline \multirow{5}{*}{10} & 10 & 3.08 & 32.00 & 46.03 & 17.25 & 1.47 & 32.15 \\
\hline & 30 & 2.5 & 33.90 & 49.12 & 19.26 & 1.50 & 33.99 \\
\hline & 60 & 2 & 34.80 & 54.78 & 21.54 & 1.51 & 34.86 \\
\hline & 90 & 0.89 & 35.20 & 55.57 & 22.38 & 1.55 & 35.21 \\
\hline & 120 & 0.11 & 35.63 & 56.79 & 23.08 & 1.57 & 35.63 \\
\hline
\end{tabular}

Table 3

The effect of Okoron 12 concentration on chromatic parameters of walnuts shell

\begin{tabular}{|c|c|c|c|c|c|c|c|}
\hline C, \% & t, $\mathbf{m i n}$ & $\mathbf{a}$ & $\mathbf{b}$ & $\mathbf{L}$ & $\boldsymbol{\Delta E}$ & $\mathbf{h}$ & $\mathbf{C}$ \\
\hline \multirow{4}{*}{1} & $\mathbf{1 0}$ & 4.92 & 29.67 & 40.19 & 5.64 & 1.40 & 29.27 \\
\cline { 2 - 8 } & $\mathbf{3 0}$ & 4.21 & 30.16 & 43.35 & 6.32 & 1.43 & 30.16 \\
\cline { 2 - 8 } & $\mathbf{6 0}$ & 3.56 & 31.1 & 44.81 & 11.81 & 1.46 & 31.10 \\
\cline { 2 - 8 } & $\mathbf{9 0}$ & 3.02 & 33.60 & 45.19 & 5.99 & 1.48 & 33.60 \\
\cline { 2 - 8 } & $\mathbf{1 2 0}$ & 2.80 & 35.16 & 45.52 & 12.85 & 1.49 & 35.16 \\
\hline \multirow{4}{*}{5} & $\mathbf{1 0}$ & 4.03 & 29.88 & 42.09 & 3.76 & 1.44 & 30.88 \\
\cline { 2 - 8 } & $\mathbf{3 0}$ & 3.40 & 30.25 & 46.13 & 11.47 & 1.46 & 31.95 \\
\cline { 2 - 8 } & $\mathbf{6 0}$ & 2.56 & 32.89 & 49.09 & 12.79 & 1.50 & 33.89 \\
\cline { 2 - 8 } & $\mathbf{9 0}$ & 1.89 & 35.49 & 50.32 & 15.40 & 1.52 & 35.49 \\
\cline { 2 - 8 } & $\mathbf{1 2 0}$ & 1.60 & 36.13 & 52.09 & 24.31 & 1.53 & 36.13 \\
\hline
\end{tabular}

Whitening effect of Okoron 12 is due to its active component peracetic acid. The main reaction of peracetic acid with phenol and ether phenols are shown in Figure 2 being typical for the hydroxylation of aromatic rings and their oxidation in ortho- and para-quinones. The oxidised ring is fragmented in muconic acid and ester structures [15]. 

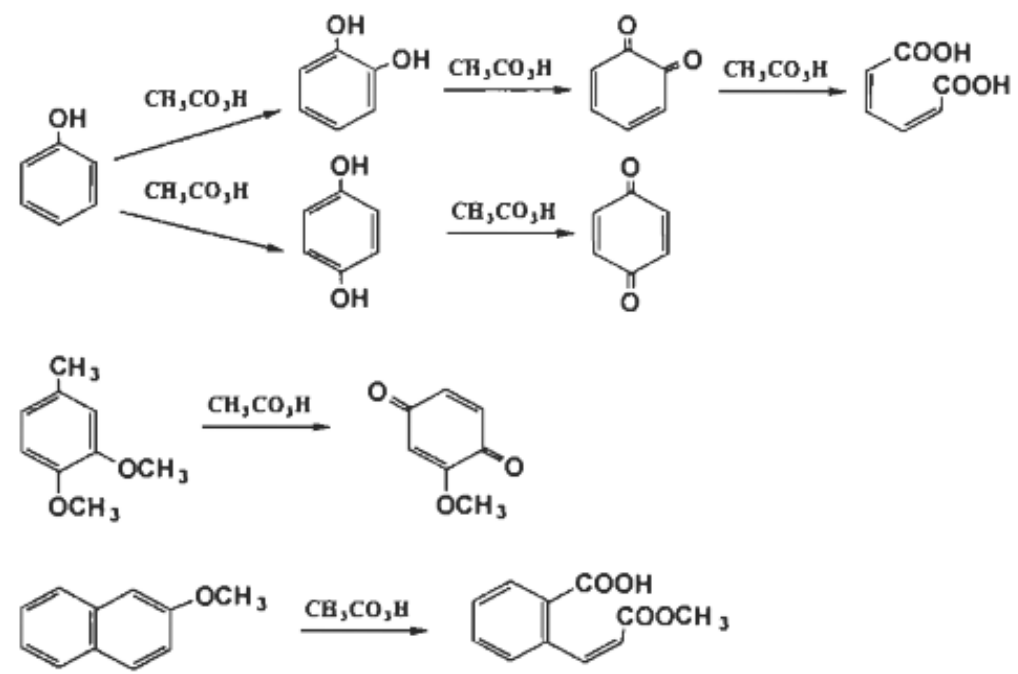

Figure 2. Oxidation of lignin compounds by peracetic acid

Table 4

The effect of Sodium perborate $\mathrm{Na}_{2} \mathrm{~B}_{2} \mathrm{O}_{4}(\mathrm{OH})_{4}$ concentration on chromatic parameters of walnuts shell

\begin{tabular}{|c|c|c|c|c|l|l|l|}
\hline C, \% & t, $\min$ & $\mathbf{a}$ & $\mathbf{b}$ & $\mathbf{L}$ & $\mathbf{\Delta E}$ & $\mathbf{H}$ & $\mathbf{C}$ \\
\hline \multirow{4}{*}{1} & 10 & 4.6 & 29.8 & 57.56 & 21.26 & 1.42 & 30.15 \\
\cline { 2 - 8 } & 30 & 3.9 & 30.6 & 60.04 & 21.96 & 1.44 & 30.85 \\
\cline { 2 - 8 } & 60 & 2.89 & 31.12 & 63.59 & 22.62 & 1.48 & 31.25 \\
\cline { 2 - 8 } & 90 & 2.52 & 31.4 & 66.51 & 23.44 & 1.49 & 31.50 \\
\cline { 2 - 8 } & 120 & 1.98 & 31.9 & 70.64 & 25.15 & 1.51 & 31.96 \\
\hline \multirow{4}{*}{5} & 10 & 2.63 & 30.2 & 65.48 & 22.49 & 1.48 & 30.31 \\
\cline { 2 - 8 } & 30 & 2.1 & 31.5 & 61.41 & 23.19 & 1.50 & 31.57 \\
\cline { 2 - 8 } & 60 & 1.84 & 32.2 & 71.26 & 28.78 & 1.51 & 32.25 \\
\cline { 2 - 8 } & 90 & 1.4 & 33.08 & 73.34 & 29.22 & 1.53 & 33.11 \\
\cline { 2 - 8 } & 120 & 1.2 & 33.2 & 73.56 & 31.10 & 1.53 & 33.22 \\
\hline
\end{tabular}

Analyzing the presented data Sodium perborate dimierized $\left[\mathrm{Na}_{2} \mathrm{~B}_{2} \mathrm{O}_{4}(\mathrm{OH})_{4}\right]$ was found to be the most effective bleaching agent. Its bleaching action is due to its property to decompose rapidly in aqueous solution generating hydrogen perroxide according to the reaction:

$$
\mathrm{Na}_{2}\left(\mathrm{H}_{4} \mathrm{~B}_{2} \mathrm{O}_{8}\right)+4 \mathrm{H}_{2} \mathrm{O} \rightarrow 2 \mathrm{Na}\left[\mathrm{B}(\mathrm{OH})_{4}\right]+2 \mathrm{H}_{2} \mathrm{O}_{2}
$$

The advantage of using sodium perborate is that it is not necessary to add sodium hydroxide, for alkalinization of the environment because the sodium borate from the 
reaction has an alkaline reaction with a $\mathrm{pH}$ value of about 10.5. In addition, at high temperatures sodium perborate is more active than hydrogen peroxide. These two features make the perborate to be considered a reliable and effective whitening agent [16]. Sodium perborate releases oxygen rapidly at temperatures over $60{ }^{\circ} \mathrm{C}$. To make it active at lower temperatures $\left(40-60^{\circ} \mathrm{C}\right)$, it has to be mixed with a suitable activator, typically tetraacetylethylenediamine (TAED) [17].

The obtained results show that the walnuts shell brightness $(L)$ increases with increasing perborate concentration, yellow hue decreases (increases the value of component b). The maximum value of brightness is reached after $60-80$ minutes of imersing in bleaching agent. The results have shown that bleaching speed increases significantly with increasing ambient temperature from 20 to $60^{\circ} \mathrm{C}$.

The mechanism of bleaching with sodium perborate is similar to the mechanism of bleaching with hydrogen peroxide. As it was mentioned hydroperoxide anion ( $\left.\mathrm{HOO}^{-}\right)$ attacks practically all organic structures, including those that contain hydroxyl and ethereal bonds [18]. Similar reactions occur and treated with sodium perborate, but its alkalinity is higher than that of hydrogen peroxide; in this respect, sodium perborate has the most significant effect on the process of delignification at the same concentration of active oxygen [19].

Total color difference $\mathbf{E}$. The total color difference (E) values at different concentration of bleaching agents are shown in tables 1-4. It is clear that $\mathrm{E}$ values were affected by the concentration for all tested agents. For all bleaching agents, E increased with the increased concentration. For example, when using $\mathrm{H}_{2} \mathrm{O}_{2}$, the $\mathrm{E}$ increased from 23,81 to 25.75 when the $\mathrm{C}(\%)$ increased from 3 to $10 \%$. A similar trend was also observed for the rest of used agents. The results indicate that the walnuts shell tends to get lighter as the concentration increased due to increased amount of active components.

\section{Conclusion}

Colour is one of the most important quality attributes influencing consumer food choices, perceptions and purchase behaviour. Colour measurement and analysis is therefore important in postharvest handling and biopro-cessing to optimize the quality and value of food. There were quantified chromatic characteristics of walnuts in shells by CIELAB system and conducted experimental studies on theyr bleaching with oxidizing agents (hydrogen peroxide, Okoron 12 calcium hypochlorite and sodium perborate).

By analyzing the color parameters values $\mathrm{L}, \mathrm{a}$ and $\mathrm{b}$ there have been studied the effects of independent parameters of bleaching and their interactive effects on the color profile and on walnut shell bleaching process.

It has been found that oxidative bleaching agents are more effective, and that whitening depends on the concentration of agents, the temperature and $\mathrm{pH}$ of the medium and walnuts lasting retention in bleaching environment. After blanching nuts shell, bleaching agents studied form the following series:

$$
\mathrm{Na}_{2} \mathrm{~B}_{2} \mathrm{O}_{4}(\mathrm{OH})_{4}>\text { Okoron } 12>\mathrm{H}_{2} \mathrm{O}_{2}>\mathrm{Ca}(\mathrm{ClO})_{2}
$$

Considering the activity of bleaching agents and their toxic emissions, walnuts can be bleached with $\mathrm{Na}_{2} \mathrm{~B}_{2} \mathrm{O}_{4}(\mathrm{OH})_{4}$ (concentration $5 \%$, pH-10, temperature $-60{ }^{\circ} \mathrm{C}$, retention time $-40-50 \mathrm{~min}$ ). 


\section{References}

1. Labuckas D.O., Maestri D.M., Perello M., Martinez M.L., Lamarque A.L., (2008), Phenolics from walnut (Juglans regia L.) kernels: antioxidant activity and interactions with proteins, Food Chemistry, 107, pp. 607-612.

2. Ramos D.E. (1998), Walnut Production Manual, University of California, Division of Agriculture and Natural Resources, Oakland, California, Publication 3373.

3. Foreign Agricultural Service (2017), Tree Nuts: World Markets and Trade.

4. Wei Q., Ma X.H., Zhao Z., Zhang S.S., Liu S.C. (2010b), Antioxidant activities and chemical profiles of pyroligneous acids from walnut shell, J. Anal. Appl. Pyrol., 88(2), pp. 149-154, DOI:10.1016/j.jaap.2010.03.008

5. Yarborough D.K., (1991), The safety and efficacy of tooth bleaching: a review of the literature 1988-1990, Compendium of Continuing Education in Dentistry, 12(3), pp. 191196.

6. Dahl J.E., Pallesen U. (2003), Tooth bleaching - a critical review of the biological aspects, Critical Reviews in Oral Biology and Medicine, 14(4), pp. 292-304.

7. Robert I., Lazau R. (2014), Dyes and pigments, 105, p. 152.

8. Pop M., Lupea A.X., Popa S., Gruescu C., (2010), Int. J. of Food Prop., 13(4), p. 771.

9. Driscoll R.H., Madamba, P.S. (1994), Modeling the browning kinetics of garlic, Food Australia, 46, pp. 66-71.

10. Moss J.R., Otten L. (1989), A relationship between color development and moisture content during roasting of peanut, Canadian Institute of Food Science and Technology Journal, 22, pp. 34-39.

11. Salvador A., Sanz T., Fiszman S.M., (2007), Changes in color and texture and their relationship with eating quality during storage of two different dessert bananas, Postharvest Biology and Technology, 43, pp. 319-325.

12. Bernalte M.J., Sabio E., Hernandez M.T., Gervasini C. (2003), Influence of storage delay on quality of "Van" sweet cherry, Postharvest Biology and Technology, 28, pp. 303-312.

13. Suess H.U. (2010), Pulp Bleaching Today, Walter de Gruyter, Berlin.

14. Milovidova L.A., Komarova G.V., Koroleva T.A., (2005), Otbelka tselliulozy, AGTU, Arkhangelsk.

15. Proulx Lyne (1998), Effet de l'acide peracétique sur la pâte thermomécanique, Mémoire, Trois-Rivières, Université du Québec à Trois-Rivières, p. 109.

16. Lopez F., Diaz M.J., Eugenio M.E., Ariza J., Jimenez L. (2002), Hydrogen peroxide and sodium perborate bleaching of pulp from olive tree residues, Eng. Life. Sci., Wiley-Vch, Weinheim, pp. 201-208.

17. Bayça S.U., Köseoğlu K., Batar T. (2004), Mineral and compound of Boron essential use in industrial area, J. Vocational School and Technical Science of Soma, 2, pp. 1-21.

18. Onur Tolga Okan, Ilhan Deniz, Ibrahim Yildirim (2013), Bleaching of Bamboo Kraft-AQ Pulp with Sodium Perborate Tetrahydrate (SPBTH) after Oxygen Delignification, Bio Resources, 8(1), pp. 1332-1344.

19. Pesman E., Kalyoncu E.E., Kirci H. (2010), Sodium perborate usage instead of hydrogen peroxide for the reinforcement of oxygen delignification, Fib. and Tex. in Eastern Europe, 18, 6(83), pp. 106-109. 